\title{
Phenomenology of Religion and the Grammar of "God"
}

\author{
ALEJANDRO TOMASINI BASSOLS
}

\section{Introduction}

A probably trivial truth is that Wittgenstein invented a particular technique for philosophical clarification, known as 'grammatical analysis'. What, on the other hand, is probably not so trivial is the fact that this kind of analysis emerged out of a different method that Wittgenstein for some time adopted and of whose limitations he little by little became aware until he finally rejected it. I have in mind the phenomenological method or approach. Regardless of how historically phenomenology has been understood and practiced, for Wittgenstein it was always the study of "immediate experience", that is, the study of what is given to consciousness in a straightforward way. It seems to be an established fact that towards the end of the 20s, after his return to Cambridge, and probably under the influence of Russell's thought and in particular of his crucial notion of "knowledge by acquaintance", Wittgenstein toyed for a while with the idea of a "phenomenological" or "primary" language. I don't think we could include without further ado the Tractatus as falling within the scope of this tendency or approach, for the nature of its objects is a highly debatable issue and because, in that book, Wittgenstein himself just dismisses the theory of knowledge in general. With respect to phenomenology, one central idea was that a logically correct notation or symbolism would enable us to account for "the given", a philosophical task for which natural language was considered as rather useless. Now while polishing his views Wittgenstein began to replace the phenomenological approach and everything it entails, as solipsistic and idealist temptations, by a new one, an approach which fitted better with what was a clearer conception of the nature of philosophy and of its functions. The new approach had as a fundamental goal not so much to take us to phenomena themselves or to things themselves as to reveal the essence of what was being talked about by stating the rules of use of the

Phenomenology as Grammar (Ed. Jesús Padilla Gálvez), 97-107.

(C) Ontos Verlag, Frankfurt a. M. 
relevant words, that is, the rules of their depth grammar. It was only through them that the nonsensical character of philosophical assertions could be exhibited and the philosophical puzzle with which we would be struggling be disposed. From this new perspective, the phenomenological approach was simply the outcome of an oversimplification and of a number of misunderstandings concerning the functioning of language, and so it had to be rejected. What replaced it was the grammatical approach.

\section{From Phenomenology to Grammar}

The idea of a phenomenological language in Wittgenstein's sense is the idea of a language composed of signs which would function as labels, that is, as names for objects. This is important, for it enables us to reject the charge of "linguistic idealist" something of which occasionally he has been accused. The truth is that it is senseless to ascribe to Wittgenstein any idealist stance whatsoever, just because the mere naming of something, i.e., the nominal baptism, alters absolutely nothing in the object's nature or in its appearances. The man Napoleon doesn't change at all just by being baptized with a different name. He might be identified in different ways, but his nature would remain exactly the same. He's not modified by my naming him either linguistically or mentally, since naming is an external relation to the object and therefore leaves him untouched. The name serves only to point to him, to allow us to (so to speak) fish him out from the ocean of objects. On the other hand, it is perfectly understandable that since we are above all visual beings (much less smelling ones than, for instance, dogs and much less tactile ones than, say, snakes), the Wittgensteinian idea of phenomenological analysis had to be related mainly to visual objects, as colours, and more generally to our visual field and what is to be found in it. Moreover, we shouldn't let pass unnoticed that if the idea of phenomenological analysis, that is, the analysis of immediate experience, is important, it is because it carries with it the idea of a final point, of an end after which we find ourselves face to face with the ultimate objects of reality, the genuine objects, the stuff of the world.

As Prof. J. Hintikka has convincingly argued, Wittgenstein's views on language went through radical changes at the end of the $20 \mathrm{~s}$ and the beginning of the 30s, changes which made him abandon the phenomenological project which so far he had favoured. This evolution was 
particularly fruitful for Wittgenstein (and therefore for us!), for it is evident that the phenomenological programme could be hardly successful in a different context than that of visual experience. If we examine Wittgenstein's writings from Philosophische Bemerkungen till The Blue Book, going through The Big Typescript and Philosophische Grammatik, what we can't avoid noticing is that all his analyses and discussions having to do with experience concern almost exclusively visual themes. Of course, there's nothing surprizing in this, since those issues had been inherited from the Tractatus and Wittgenstein felt that he still had to deal with them. This is the case of, for instance, the problems concerning the logic of colour, which forced Wittgenstein to carry out extremely detailed and complicated analyses of visual situations and colour relations. It is obvious that normal visual experience is not an hallucination, but how are we supposed to distinguish the perception of a coloured object from the having in our visual space a coloured patch? In the same vein, how are we supposed to give an account of the transitions among colours, that is, how are we to explain that there can be a yellowish red but not a greenish red or how we pass from red to yellow? Indeed, Wittgenstein's visual analyses are totally original and it would be very difficult to find antecedents of them in the history of philosophy. There's simply no tradition which they could be associated with. But they become understandable if we see them as arising from Wittgenstein's need to solve difficulties related to his logical and phenomenological approach. From this point of view, problems which at first sight seem to be utterly redundant or artificial suddenly acquire a definite sense. Now, regardless of what I've stated, one thing is clear, namely, that for Wittgenstein at the beginning of the 30 s visual experience, stated in terms of a primary language, had warranted its accusatives: visual experience was always (i.e., under normal conditions) experience of something.

What I've very roughly described points to a quite interesting and even exciting subject-matter, but there was a problem: there is no question that we have a whole range of experiences, a variety of them, sets of experiences which are far more complex than visual ones and which were not reducible to primary or basic experiences. But then: how would it be possible to give a phenomenological account of them? In particular, it can hardly be denied that there is such thing as "religious experience", but what is the accusative of, say, a mystical experience? What is its object, the thing or the phenomenon 
which would in principle constitute the content of the experience itself, the thing to which one would be immediately related? Let's recall that already in the Tractatus Wittgenstein had stated that "God does not reveal himself in the world". But what this implied was, among other things, that the phenomenological approach meant the end of rational inquiry about so important an issue: in the case of religious experience, and probably in many others as well, there was simply no accusative to point to and to get in touch with. Such an outcome could only mean an impoverishment of philosophical inquiry, which was then forced to reserve all the important subjects to the sphere of silence. It was then obvious that the phenomenological perspective had very narrow limits set up a priori: there would always be countless subjects, among which we would have to include moral issues, artistic creativity and enjoyment and of course religious experience about which the only way we could eventually have to transmit something would be by saying nothing. Such a perspective, therefore, had to be acknowledged as a complete failure. Probably Wittgenstein got rid of the phenomenological approach for many other reasons as well, that is, for a number of explanatory holes or failures it gave rise to. All these were the internal limitations of phenomenology itself. So quitting the phenomenological approach did represent a rather happy event for philosophy in general and for the philosophy of religion in particular, as I shall argue now.

I don't think that one could put into question the idea that the grammatical approach is not only much more fruitful than the phenomenological one, but also that it fits better with Wittgenstein's conception of philosophy and of philosophical difficulties. It enabled Wittgenstein, for example, to get rid once and for all of all sorts of temptations concerning quasi-empirical or pseudo-empirical kinds of analysis, but above all it reinforced Wittgenstein's inclination in favour of the linguistic perspective. Needless to say, Wittgenstein's linguistic turn didn't entirely coincide with Austin's or Ryle's conception of linguistic philosophy. From Wittgenstein's point of view, the genuine philosophical exercise had to consist of an examination of uses and applications of words, which required the philosopher to be familiar with their normal background. So this kind of philosophical analysis inevitably takes us beyond the realm of signs to locate us in the realm of human action, that is, of intentional and meaningful movements, regardless of their context (mathematical, artistic, religious, 
moral and so on). Religious experience or moral life went on representing for him actual poles of interest, but fairly soon it dawned on him that the introspective, pseudo empirical or existential kind of analysis, however detailed they could be, had to be abandoned as a mechanism for philosophical clarification. Experiences are valuable and do reveal something about the person who has them, but the point is that the mere description of their supposed content amounts to nothing philosophically significant. Of course there is such a thing as religious experience, but it is neither introspection nor the study of its qualia what would help us to understand it. So not too much later Wittgenstein's return to Cambridge, the "name-object" model, the Augustinian conception of meaning had already been completely overcome. By the time the Brown Book had been produced, it was clear that phenomenology was just useless for the understanding of religious experience. With respect to the latter, the task was to give an account of it assuming no accusatives at all, that is, presupposing no special objects with which the subject could eventually get in touch. Now the new approach demanded new methods and a new conception of what philosophical research had to consist in. In other words, it was thanks to the rejection and abandonment of the phenomenological kind of research in favour of the grammatical one that Wittgenstein's new way of thinking was in a position to open itself to religious experience and to offer a much more satisfactory philosophical explanation of it.

\section{The rules of Grammar}

Trying not to be dogmatic, I think we could say that the idea of "depth grammar" (Tiefengrammatik), something which obviously has nothing in common with the Chomskian idea of "deep grammar", plays in Wittgenstein's later conception of language a similar role to the one played by logic and logical form in the context of the Tractatus. To put it briefly, the rules of grammar are the rules of language which inform us what kind of objects there are, since in a sense they constitute them. The rules of depth grammar give us the essence of objects once we conceive them from the perspective of the use of words and the way they are identified by speakers. It is evident, I assume, that to assert that words literally constitute objects is to assert something absurd. The idea is rather that objects may be constituted 
linguistically in the sense that every time we are asked what the nature of an object is what we offer as an answer is a rule of grammar. Naturally, from this point of view purely formal considerations are entirely irrelevant. Here such notions as "a priori", "necessary", "true in all possible worlds" and so forth are just useless. The rules of grammar fix the use of words, use being considered as totally independent from the classifications of surface grammar. Accordingly, the rules of grammar are retrieved or recovered by means of sentences which prima facie at least have no special status. For instance, rules of grammar cannot be understood as analytical nor as true in all possible worlds. Nevertheless, there is a sense in which they are necessary, while being at the same time synthetic. But it would be utterly misleading to refer to them as "synthetic a priori", since they are not a priori in the sense of "being true independently of experience". If we speak of them as being "a priori" it is simply because the meaning of what we say is delimited by what they state, but in spite of being a priori in this sense, it is clear that they could have been different. To put it paradoxically, the rules of depth grammar are contingently necessary. If this conflicts with some well established theorem of modal logic, so much the worse for modal logic. Finally, it is worth pointing to a curious feature of these rules, which could be called their "double aspect" feature. What I mean is that in the context of normal speech, that is, non philosophical discourse, the rules of grammar state nothing but trivialities, platitudes, whereas used in philosophical contexts they become all important, for it is by their means that philosophical theses can be blocked, since we can then point out exactly where philosophers carried out their the semantic transgression.

It is obvious that language is not learnt by learning rules of grammar (or rules in any sense whatever). Rules are implicit in our use of words. We cannot deduce them formally from our assertions. Rather, we have to dig them out from the philosophical ground in which we find ourselves. Neither can we find them by means of, say, transcendental arguments. Rules of grammar enable us to separate what has a sense from what is meaningless and of course Wittgenstein's insight was that all philosophical assertions always constitute a violation of the rules of grammar. Since this violation doesn't conflict with the rules of surface grammar, the semantic offense can pass unnoticed. Needless to say, hardly anybody has a perspicuous representation of our systems of grammatical rules. It is only when one has managed to have 
a synoptic view of such rules that the philosophical difficulty that troubles us vanishes and that one can rest.

What I've been saying holds equally for words like 'number', 'knowledge', 'truth', 'meaning', 'existence' and so on as it does for religious terms, like 'faith', 'prayer', 'sin', etc., and obviously 'God'. I'll now examine the concept of God, taking of course into account what I've been saying about the rules of depth grammar in general.

\section{The usefulness of "God"}

Following a suggestion by G. H. von Wright, I think that the best adjective to refer to the Wittgensteinian conception of language is 'praxiological'. If we accept this characterization, lots of things Wittgenstein says become easier to grasp and to appreciate. So concerning religion Wittgenstein was interested in drawing the boundaries of experience and action, that is, of the forms of life that religious language-games conform or delineate. It goes without saying that the faithful description of the utility of the term 'God' excludes all sorts of cognitive aims. The clarification of the meaning of 'God' requires us to have an insight into its corresponding rules of grammar. Whoever intends to employ the word 'God' as a term belonging to the language-games of scientific knowledge and truth will automatically be violating its depthgrammar rules.

It follows from what I've said that the rules of language in our sense cannot be guessed. How then do we trace them? The only thing we can do to ferret them out is to analyze particular cases in which the term is correctly applied. The rules of grammar are just those semantic principles which underlie and justify our legitimate moves in the various language-games which we have recourse to. Let's then see where this idea leads us.

I don't think it's misguided to assert that, throughout both history and the history of philosophy, the concept of God has been used mainly in two different ways. There has been, first, a cognitive and explanatory concept of God and, secondly, a moral and practical one. With the Tractatus the former was simply ruled out. Within the context of knowledge (the explanation of the world and life), 'God' just means that we have arrived at the limits of our explanations and that there remains nothing else to ask about. For instance, 
natural phenomena are explained, in the sense that we are told why they happen and how it is that they happen, by appealing to the laws of science, some of them being thought of as laws of nature. But if now we are asked why such laws are what they are, the only possible answer is to say that they are what they are because that's the way God decided them to be. Now this is not to give a new kind of knowledge, but a way of saying that there is no further explanation to get, not only that our cognitive powers are utterly unable to provide an answer for such questions but rather that they make no sense at all. Clearly, this is what Wittgenstein wants us to be convinced of when, in 6.372, he points out that in this respect the Ancients were more profound that Modern philosophers, who tend to think that everything can be explained. Now, assuming that the explanatory concept of God has indeed been eliminated: does the same happen with the moral concept of God?

The answer is: of course not! Already in the Notebooks, Wittgenstein makes a series of assertions in which he highlights the practical nature and the indispensable character of the moral concept of God. We can point to at least three crucial connections in this sense. So we have:

a) the idea of God as a father

b) the idea that conscience is the voice of God

c) the idea that happiness is the acting in accordance with God's commandments

Although these ideas are all important, the truth is that in his first writings Wittgenstein presents them as the outcome of some sort of inspiration. He offers no justification of them. Now, however, we understand that he could offer no phenomenological explanation of them, no clarification at all of the meaning of statements like 'God is what makes me happy', 'God tells me what I ought to do' and so on. The explanation of these kinds of assertions would be available only after the language paradigm had changed and the phenomenological approach totally abandoned in favour of the grammatical one. Let's try to make this clear.

The mature Wittgenstein's philosophy, a philosophy which takes shape through the application of a new conceptual apparatus (mainly "seeing as", "language-game", "form of life", "family resemblance", "criterion", "perspicuous representation", "grammar") to philosophical situations, that is, to conceptual tangles which have the appearance of insoluble problems, offers the possibility of real elucidations where the Tractatus ends and can explain 
no more. It was the detailed description of the use of religious terms in a variety of situations what enabled Wittgenstein to discover that what we call 'religious language' is basically a language of images, these being characterized by the peculiar utility they lend to normal speakers. But we can see now that the use Wittgenstein had made of the concept of God in, say, the Notebooks, is precisely the use of an image. Obviously, to speak of God as a father or to speak of the voice of God is not to speak literally (only a fanatic, I suppose, could ever imagine that God expresses Himself in his language!). So however darkly, the idea that religious assertions are possible by having recourse to images was already present in the young Wittgenstein's thought. Given that, strictly speaking, we can elaborate no proposition about God, the status of what Wittgenstein says about Him had to remain unexplained and misunderstood. In order to really grasp what expressions like 'Conscience is the voice of God' mean, and many others similar to it, Wittgenstein's second philosophy had first to be developed.

In this as in many other cases, it is important to distinguish between religious propositions (or better: legitimate moves in the various religious language-games) and grammatical propositions about such and such a religious concept. This is not always easy to achieve. Before trying to clarify this issue, let me first show the difference between those two groups of sentences by means of examples.

Moves in religious

language-games

a) God will punish you!

b) I'll come back safely to

Mexico, if God permits

c) I know that God will forgive me

d) God will not allow you to do that!
Grammaticalpropositions

concerning religious expressions

a') God sees everything

b') Everything is in God's hands

c') God is infinitely good

d') God is in your heart

People learn concepts by applying the corresponding words and by watching how they are used in the appropriate situations by other people, but they really attain a proper intellection of them only when they succeed in having a perspicuous representation of their grammatical rules. Thus, thanks to the grammatical approach we are in a position not only to separate what makes sense from what doesn't, but also to understand the nature of religious 
experience, which is what phenomenology was supposed to give us. For instance, no one can say that he or she had a horrible mystical experience, for that makes no sense and it is senseless because (and here we bring in another grammatical rule) the contemplation of God is what constitutes happiness.

At this stage there arises a problem, one which we also have to face within, for instance, the philosophy of mathematics. Thus although numbers serve to carry out operations, anyway we tend, induced by surface grammar, to reify them. Given that this way of interpreting them doesn't correspond to or fit with their use, we immediately find ourselves in the problem of giving an account of the nature of numbers in a totally independent way from their real utility or usefulness. The same happens with 'God': we tend, under the influence of surface grammar, to overlook the real services it lends, and so we spontaneously reify Him and then, for example, we can't avoid falling into the absurd and eternally failed attempt to offer proofs of His existence. In the case of God the issue is still more complex, for it would seem that in order to make sense of religious practices, as prayer, invocations, manifestations of acceptance of fate, and so forth, God has to be imagined as theists "visualize" Him, that is, as a living supernatural being, with whom they can interact, develop a personal relationship, etc. And so it could be argued that were this reification unavoidable, then it would have been shown that there is no other possibility to understand the language of God than in the fashion of theism. We would then be back to traditional, rational theology

I think that Wittgenstein's remarks about religious language help us out of this problem. Wittgenstein showed that religious language is articulated by means of images, images which we adopt not so much through arguments as by being inculcated to us. Such images have multiple applications and they may become indispensable for speakers. Now if we do understand that religious language cannot be taken literally, as mere factual language, and if the grammatical clarifications did enable us to grasp its real utility (the kind of thing it enables us to say and, accordingly, the kind of experience we can in principle enjoy), then the supposed reification induced by surface grammar becomes neutralized and harmless. The belief in God as in a supernatural being arises out of misunderstanding or ignoring, so to speak, the logic of the use of the term. If we do understand that what is at stake is nothing but an image, the search for an entity becomes an extravagant intellectual adventure, proofs of existence and non existence utterly irrelevant, and so on. It'll no 
longer will matter to us that necessarily 'God' appears as the subject of sentences: with the rules of grammar in view, the traditional temptation to reify Him just breaks down.

\section{Final remarks}

It could hardly be denied that the grammatical approach suddenly opened up a new horizon of philosophical debate, actually a new range of subjects. There is no doubt that religion enormously benefited from this. From this new perspective, it became feasible to distinguish and separate moves in the language-games from the constitutive rules of the game itself, meaningful assertions from senseless ones (however correct they are from the point of view of surface grammar), genuine subjects from spurious themes (as, for instance, the efforts to demonstrate the existence of God). The fact that in contemporary philosophy and, however surprizing, in the self-called 'analytical philosophy', very few philosophers make serious efforts to carry out grammatical analyses and that the study of Wittgenstein has been reduced to a kind of theological exegesis, cannot hide the truth that the transition from the phenomenological to the grammatical approach is a clear example of what could be called 'genuine philosophical progress'. 
